\title{
Cognitive and functional competence after anaesthesia in patients aged over 60: controlled trial of general and regional anaesthesia for elective hip or knee replacement
}

\author{
M J T Jones, S E Piggott, R S Vaughan, A J Bayer, R G Newcombe, T C Twining, J Pathy, \\ $M$ Rosen
}

\begin{abstract}
Objective-To determine the influence of general or regional anaesthesia on long term mental function in elderly patients.

Design-Prospective study of patients randomly allocated to receive general or regional anaesthesia.

Setting-The patients' homes and a large teaching hospital in Cardiff.

Subjects - 146 Patients aged 60 and over scheduled for elective hip or knee replacement.

Main outcome measures-Scores achieved in tests of cognitive function and functional competence.

Results -72 Patients were allocated to receive general anaesthesia and $\mathbf{7 4}$ regional anaesthesia. Anaesthetic technique did not influence the duration of the operation, time to mobilisation postoperatively, requirements for analgesia after the operation, or duration of stay in hospital. Three months after the operation there was an improvement in the score for the recognition component ( $76 \mathrm{ms,} \mathrm{95 \%}$ confidence interval 9 to 144) and the response component ( $82 \mathrm{~ms}, 5$ to 158 ) of the choice reaction time in the group receiving general anaesthesia compared with the group receiving regional anaesthesia. This was the only significant difference between the two groups in the assessments of cognitive and functional competence. Eleven patients receiving regional anaesthesia and 12 receiving general anaesthesia reported that their memory and concentration were worse than before the operation, but this was not confirmed by testing.

Conclusion-Cognitive and functional competence in elderly patients was not detectably impaired after either general or regional anaesthesia when attention was paid to the known perioperative influences on mental function.
\end{abstract}

College of Medicine Cardiff CF4 4XW

M J T Jones, FCANAES, clinical research fellow S E Piggott, FCANAES, clinical research fellow A J Bayer, $\mathrm{MB}$, lecturer in geriatrics

R G Newcombe, PHD, senior lecturer in medical statistics

T C Twining, PHD, clinical psychologist

J Pathy, FRCP, professor of geriatric medicine

University Hospital of Wales, Cardiff CF4 4XN R S Vaughan, FCANAES, consultant

M Rosen, FCANAES, consultant

Correspondence to: Dr M J T Jones, Princess of Wales Hospital, Bridgend, Mid-Glamorgan CF31 1RQ.

BrMed F 1990;300:1683-7

\section{Introduction}

As the total and relative numbers of people who are of pensionable age increase so will the number of such people presenting for surgery, both emergency and elective, thus increasing the demand on services and resources.' Anaesthetists who care for and manage this group of patients will want to select an anaesthetic technique that produces minimal morbidity and mortality. An impairment that is not resolved by the time the patient is discharged from hospital could have long lasting social and economic consequences.

There is a commonly held belief that elderly patients are "never the same" after admission to hospital. The long term effects of admission to hospital, surgery, and anaesthesia remain unclear. The initial investigations into the part played by anaesthesia in any postoperative deterioration in mental function were inconclusive and at times contradictory. ${ }^{23}$ There is some evidence that hyperventilation may cause a detectable impairment of certain mental functions in elderly patients. ${ }^{45}$ Even when patients seemed to have been protected from adverse events such as hypoxia ${ }^{6}$ and hypotension ${ }^{7}$ there were still unexplained detectable alterations in mental function. ${ }^{9-12}$ The evidence of impairment of psychomotor fuction in elderly patients commonly applies only to the early postoperative period. ${ }^{7^{13}}$ Studies on the long term effect of anaesthesia on cognitive performance in elderly patients have had methodological faults, such as no randomisation to anaesthetic technique, ${ }^{311}$ no assessment before admission, ${ }^{14}{ }^{15}$ and inclusion of patients of all ages. ${ }^{16}$

We compared the long term effects of a standardised general and regional anaesthetic technique on patients aged over 60 after excluding other possible deleterious effects of admission to hospital and operation.

\section{Patients and methods}

The names, ages, and addresses of all patients scheduled for admission for hip or knee replacement were collected weekly from the orthopaedic department. Patients aged $\geqslant 60$ who lived within $48 \mathrm{~km}$ of the hospital were sent a letter inviting them to agree to home visits by a psychologist before and after their operation, at which data on the possible effects of admission to hospital and of the operation on various mental functions including memory would be collected. Patients were told that the tests would take about 40 minutes and that it would be helpful if a relative could be present at the time of testing. At this stage we sought consent only for psychometric testing, consent for the anaesthetic procedure being obtained after assessment by an anaesthetist and randomisation to one of the treatment groups. ${ }^{17} 18$

If the patient agreed to take part, an appointment was made for a psychologist to visit. During this interview demographic and personal health details were gathered and the cognitive tests listed below were administered.

The national adult reading test $t^{19}$ is a test of premorbid 
returned was also determined. The mean of three measurements for downward and upward shifts in frequency was taken as the critical flicker fusion value.

The object learning test ${ }^{22}$ is a test of recall of everyday objects after a brief viewing period. The patients were shown four cards with $10,15,20$, and 25 pictures for $30,45,60$, and 75 seconds respectively. After each card was taken away the patients were asked to recall as many objects as possible. The total number of objects correctly recalled was used as the outcome measure.

The digit copying test $t^{22}$ is a simple measure of pyschomotor speed and information processing. Patients were asked to copy 100 digits as quickly as possible. The maximum time allowed was two minutes, and the number of digits attempted or the number of seconds required to copy all 100 was used to calculate a transformed score.

The functional life scale $e^{23}$ is a structured assessment of the functional activities of the patient in the past month, covering the activities of daily living (seven questions), home activities (eight questions), outside activities (nine questions), and social interaction (six questions). The section on cognition was not scored. Each activity was rated by the assessor on up to four aspects as appropriate: self initiation, frequency, speed, and overall efficiency. Each aspect in turn was scored between 0 (not done at all) and 4 (done normally). The scale was analysed to give scores for each section and each aspect as well as an overall score.

The cognitive difficulties scale ${ }^{24}$ is a standard self report questionnaire that measures subjective complaints including dysfunctions of attention and concentration, psychomotor coordination, orientation, and recent and long term memory. Patients were asked to choose the best of five possible responses to 39 questions about their behaviour in the past month. The individual scores were then totalled (the maximum score of 156 indicated severe deficits and the minimum of 0 indicated no deficits). The questionnaire was left with the patient to be completed and returned by post within a few days. Any questionnaire not returned by post was collected from the patient after his or her arrival in hospital.

On admission to hospital the patients were visited by an anaesthetist who was blind to the results of the assessment. Patients deemed suitable for either technique after a full history and examination were allocated to one of two treatment groups (general anaesthesia or regional anaesthesia) using a predetermined technique for concealed randomisation. The anaesthetic technique proposed was then fully explained to the patient. Both techniques are in common use.

Patients receiving general anaesthesia were given diazepam as premedication and thiopentone to induce anaesthesia followed by pancuronium. They were intubated and ventilated with oxygen, nitrous oxide, and halothane supplemented by fentanyl (up to $0 \cdot 2$ $\mathrm{mg}$ ). The blood pressure was maintained within $25 \%$ of preoperative values throughout by administering intravenous fluids and altering concentrations of halothane; normocapnia was maintained. Oxygen was continued until the patient left the recovery room. Postoperative analgesia was provided by intramuscular morphine, $10 \mathrm{mg}$ every four hours as required.

Patients receiving regional anaesthesia were given no premedication. Midazolam was given intravenously (in $1 \mathrm{mg}$ increments up to $10 \mathrm{mg}$ ) before the regional block was inserted and during the procedure as required. Spinal blockade was performed with $2-3 \mathrm{ml}$ of $0.5 \%$ bupivacaine in $8 \%$ dextrose at the L2-3 or L3-4 interspace. Blood pressure was maintained within $25 \%$ of preoperative values by giving intravenous fluids and vasopressors. Oxygen was administered from the time the patient entered the anaesthetic room to the time he or she left the recovery room. The postoperative analgesic regimen was the same as that for the group receiving general anaesthesia. Patients were not required to lie flat for 24 hours.

Patients in both groups received prophylactic antibiotic cover from the time of operation until 48 hours postoperatively. After operation each patient was visited daily until discharge. Data were collected on analgesic requirements, time to mobilisation and discharge from hospital, and complications.

Three months after operation the patients were visited at home by the psychologist, who remained blind to the anaesthetic technique. All assessments performed at the initial visit were repeated except for the national adult reading test. Additional questions were asked about the degree of satisfaction with the anaesthetic procedure and outcome of the operation, and problems that had occurred after discharge from hospital. A friend or relative present during this interview was asked for his or her assessment of how the patient had been since leaving hospital compared with before the operation.

If a patient refused a follow up visit or there was no reply to the letter requesting the follow up, the patient's general practitioner was contacted in an attempt to ascertain the reason. A control group of patients on the waiting list for major joint replacement was visited and tested twice at a three month interval to gather data on performance without the influence of admission to hospital and operation.

A sample size of 200 was estimated to give a power of 0.8 to detect a difference of $0.4 \mathrm{SD}$ between the two treatment groups, and to be recruitable within the 18 month study. Results were analysed with Student's $t$ test, analysis of variance, or the $\chi^{2}$ test as appropriate. Significance testing and estimation of confidence intervals were performed on an intention to treat basis (pragmatic approach). The results are presented in such a way as to permit subsequent adjustment for deviations in the protocol and recovery of a slightly different "explanatory" estimate, indicating what the difference might have been had it always been possible to use the treatment allocated..$^{25}$

\section{Results}

During the 18 month study 232 patients were scheduled for admission to either hip or knee replacement; 81 were excluded from the recruitment for various reasons (table I), leaving 151 patients to enter the study. Five of these were subsequently excluded because they had a second anaesthetic within three months. The remaining 146 were judged to give a power of 0.8 to detect a difference of $0.46 \mathrm{SD}$ between the groups, which was considered adequate. Seventy two patients were assigned to receive general anaesthesia and 74 to receive regional anaesthesia. There were 50 patients in the control group. Several deviations from the protocol occurred (table II), but only those patients who underwent a second anaesthetic before the three month follow up were excluded from the analysis. Nine patients who were randomised to receive regional anaesthesia actually received general anaesthesia; three refused the regional technique and in six the regional technique failed.

TABLE I-Reasons for excluding patients from study

\begin{tabular}{cc}
\hline Noof \\
Reasons \\
patients
\end{tabular}

Not living locally

Operation cancelled

Had had an anaesthetic within past 3 months

Unable to complete preoperative assessmen

Unsuitable for assessment or randomisation

Refused to take part in psychometric testing 


\begin{tabular}{lc}
\hline Deviation & $\begin{array}{c}\text { No of } \\
\text { patients }\end{array}$ \\
\hline Patient had second anaesthetic within 3 months & 5 \\
Patient had bilateral procedure during the anaesthetic & 1 \\
Patient did not complete 3 month follow up & 17 \\
Patient refused regional anaesthesia $\dagger$ & 3 \\
Regional anaesthesia failed $\dagger$ & 6 \\
\hline
\end{tabular}

$\star$ Patients were excluded from the analysis.

†Patients were analysed by intention to treat.

\section{DEMOGRAPHIC DETAILS}

The patients in each treatment group were similar with regard to age, sex, marital state, social class, home circumstances, indications for surgery, operation performed, and other preoperative variables (table III). The scores achieved in the preoperative tests of cognitive function and the assessment of functional competence and activities were similar in the two groups.

TABLE III - Sociodemographic details of patients undergoing elective surgery for joint replacement according to type of anaesthesia they were randomised to receive. Values are numbers

\begin{tabular}{|c|c|c|}
\hline & $\begin{array}{c}\text { General } \\
\text { anaesthesia } \\
(\mathbf{n}=72)\end{array}$ & $\begin{array}{c}\text { Regional } \\
\text { anaesthesia } \\
(\mathbf{n}=74)\end{array}$ \\
\hline \multicolumn{3}{|l|}{ Age (years): } \\
\hline $60-69$ & 38 & 28 \\
\hline $70-79$ & 30 & 37 \\
\hline$\geqslant 80$ & 4 & 9 \\
\hline \multicolumn{3}{|l|}{ Sex: } \\
\hline M & 19 & 20 \\
\hline $\mathrm{F}$ & 53 & 54 \\
\hline \multicolumn{3}{|l|}{ Marital state: } \\
\hline Single & 7 & 3 \\
\hline Married & 39 & 39 \\
\hline Widowed & 23 & 31 \\
\hline Divorced & 3 & 1 \\
\hline \multicolumn{3}{|l|}{ Home circumstances: } \\
\hline Lived alone & 16 & 24 \\
\hline Lived with relatives & 55 & 46 \\
\hline Other & 1 & 4 \\
\hline \multicolumn{3}{|l|}{ Social class: } \\
\hline I & 6 & 3 \\
\hline II & 21 & 16 \\
\hline III & 39 & 44 \\
\hline IV & 3 & 5 \\
\hline $\mathrm{V}$ & 3 & 6 \\
\hline \multicolumn{3}{|l|}{ Indication for operation: } \\
\hline Osteoarthritis & 57 & 55 \\
\hline Rheumatoid arthritis & 7 & 9 \\
\hline Osteoarthritis and rheumatoid arthritis & 6 & 10 \\
\hline Other & 2 & \\
\hline \multicolumn{3}{|l|}{ Operation: } \\
\hline Hip replacement ${ }^{\star}$ & 46 & 43 \\
\hline Knee replacement & 27 & 31 \\
\hline
\end{tabular}

${ }^{\star}$ One patient had both hips replaced.

\section{INPATIENT DATA}

Analysis of the inpatient data showed no evidence of any difference between the groups as regards length of preoperative stay, duration of operation, postoperative analgesia, time to mobilisation, and duration of hospital stay (table IV).

All patients who received regional anaesthesia were taking oral fluids within an hour of the end of the operation, whereas those who had general anaesthesia took from four to 24 hours to resume oral fluids. Measured and estimated losses of blood were not significantly different between the two anaesthetic techniques, but significant differences were found between the groups regarding transfusion requirements and fluid replacement. Of the patients having total hip replacement, $39(72 \%)$ receiving general anaesthesia required transfusion compared with only $22(50 \%)$ receiving regional anaesthesia $\left(p<0 \cdot 05, \chi^{2}=5 \cdot 2\right)$. Thirty three $(76 \%)$ of those having regional anaesthesia for hip replacement, however, were given a plasma expander compared with only $18(33 \%)$ of those receiving general anaesthesia $\left(p<0.001, \chi^{2}=16 \cdot 4\right)$. Estimations of haemoglobin concentrations preopera- tively and on the first and fifth postoperative days showed no difference between the groups defined by either anaesthetic technique or procedure. Mortality and the incidence of complications were similar in the two groups (table IV). The three deaths in hospital were due to massive pulmonary embolus, which was confirmed at necropsy, without any clinically detected deep vein thrombosis.

TABLE IV-Data on patients during admission to hospital for surgery according to type of anaesthesia they were randomised to receive

\begin{tabular}{lcc}
\hline & $\begin{array}{c}\text { General } \\
\text { anaesthesia } \\
(\mathbf{n}=72)\end{array}$ & $\begin{array}{c}\text { Regional } \\
\text { anaesthesia } \\
(\mathbf{n}=74)\end{array}$ \\
\hline $\begin{array}{l}\text { No of days in hospital before operation } \\
\text { (No of patients): }\end{array}$ & & \\
$\quad 1-3$ & 62 & 64 \\
$\quad 4-7$ & 3 & 8 \\
$\quad \geqslant 8$ & 7 & 2 \\
Mean (SD) duration of surgery (min) & $112(28)$ & $107(24)$ \\
Mean (SD) total dose of morphine received & $22(12)$ & $24(13)$ \\
$\quad$ after operation (mg) & $3 \cdot 2(1 \cdot 2)$ & $3 \cdot 5(1 \cdot 2)$ \\
Mean (SD) No of days until mobilised & & \\
Mean (SD) No of days in hospital after & $18 \cdot 4(9 \cdot 0)$ & $19 \cdot 9(7 \cdot 8)$ \\
$\quad$ operation & 3 & 6 \\
Complications (No of patients): & 2 & 2 \\
$\quad$ Clinical deep vein thrombosis & 1 & 2 \\
Clinical pulmonary embolus & 4 & 3 \\
Chest infection & 2 & 1 \\
$\quad$ Wound infection & & \\
\hline & &
\end{tabular}

\section{THREE MONTH FOLLOW UP DATA}

The three month postoperative follow up at home was completed by 129 patients. Sixty four had received general anaesthesia and 65 had received regional anaesthesia.

In most tests of cognitive and functional competence there was no change in score over the three months and no significant difference between the groups (table $\mathrm{V}$ ). No correlation was found between age and scores in the tests, and those who had scored poorly in the initial test session continued to do so at the three month follow up but had not deteriorated. The scores in the tests of functional competence improved in both groups (NS). The recognition and total times recorded during the measurement of choice reaction time, however, had significantly altered $(p=0.03$ and 0.04 respectively). The time taken to respond was unchanged among those who received a regional anaesthetic but significantly reduced in those who were given a general anaesthetic $(\mathrm{p}<0.05)$ - that is, performance improved after general anaesthesia.

When the patients and their relatives were asked for their opinions on the anaesthetic, the outcome of the operation, and subsequent progress most seemed to be pleased (table VI). No significant difference existed between the groups in these subjective measures with large proportions in both groups reporting an improvement in morbidity and a reduction in pain.

Seventeen patients did not complete the three month follow up assessment. Four had left the area to live with relatives and two had moved overseas. The general practitioners of the remaining 11 patients reported that the subjects were in good general health and seemed to be progressing after their operation, although several had domestic or alcohol related problems that may have resulted in their unwillingness to repeat the home visits.

When the results for the 50 control patients were examined the patients had scored similarly on all the tests both at the initial testing session and at the three month follow up. Thus we concluded that our treatment groups were representative of those patients on the waiting list for elective major joint replacement and that the tests we used were valid over three months, with no substantial improvement in the scores owing to possible learning effects 


\begin{tabular}{|c|c|c|c|c|c|c|c|}
\hline & \multicolumn{2}{|c|}{ General anaesthesia } & \multicolumn{2}{|c|}{ Regional anaesthesia } & \multirow{2}{*}{$\begin{array}{c}\text { Estimated } \\
\text { difference } \\
\text { between } \\
\text { group mean }\end{array}$} & \multirow[b]{2}{*}{$\begin{array}{l}95 \% \text { Confidence } \\
\text { interval }\end{array}$} & \multirow[b]{2}{*}{$\mathrm{p}$ Value } \\
\hline & $\begin{array}{c}\text { Before } \\
\text { operation }\end{array}$ & $\begin{array}{c}\text { After } \\
\text { operation }\end{array}$ & $\begin{array}{l}\text { Before } \\
\text { operation }\end{array}$ & $\begin{array}{c}\text { After } \\
\text { operation }\end{array}$ & & & \\
\hline \multicolumn{8}{|l|}{ Cognitive variables: } \\
\hline National adult reading test $(\mathrm{IQ})$ & $109(8 \cdot 2)$ & & $107(7 \cdot 7)$ & & $-2 \cdot 1$ & $-4 \cdot 7$ to $0 \cdot 6$ & $0 \cdot 12$ \\
\hline Object learning test (number recalled) & $37 \cdot 0(8 \cdot 9)$ & $38 \cdot 3(8 \cdot 2)$ & $35 \cdot 0(8 \cdot 7)$ & $37 \cdot 3(8 \cdot 8)$ & $0 \cdot 8$ & $-1 \cdot 1$ to $2 \cdot 7$ & $0 \cdot 41$ \\
\hline Digit copying test (transformed score) & $107(31)$ & $112(29)$ & $98(28)$ & $103(30)$ & $2 \cdot 4$ & $-3 \cdot 4$ to $8 \cdot 3$ & $0 \cdot 41$ \\
\hline \multirow{2}{*}{\multicolumn{8}{|c|}{ Choice reaction time: }} \\
\hline & & & & & & & \\
\hline Recognition (ms) & $530(177)$ & $491(114)$ & $515(190)$ & $505(154)$ & 76 & 9 to 144 & 0.03 \\
\hline Response (ms) & $854(203)$ & $803(174)$ & $824(235)$ & $823(213)$ & 82 & 5 to 158 & 0.04 \\
\hline Cognitive difficulties scale (total score) & $34 \cdot 6(23 \cdot 7)$ & $33 \cdot 2(24 \cdot 9)$ & $31 \cdot 9(22 \cdot 1)$ & $31 \cdot 1(19 \cdot 9)$ & $1 \cdot 0$ & $-5 \cdot 6$ to $7 \cdot 6$ & 0.76 \\
\hline \multicolumn{8}{|l|}{ Functional assessment ( $\%$ of maximum): } \\
\hline Activities of daily living & $70 \cdot 5(12 \cdot 0)$ & $78 \cdot 0(14 \cdot 4)$ & $70 \cdot 9(14 \cdot 4)$ & $76 \cdot 6(16 \cdot 3)$ & $0 \cdot 2$ & $-3 \cdot 5$ to 3.9 & $0 \cdot 93$ \\
\hline Home activities & $63 \cdot 0(15 \cdot 4)$ & $64 \cdot 6(17 \cdot 1)$ & $60 \cdot 0(18 \cdot 1)$ & $60 \cdot 4(18 \cdot 7)$ & -0.8 & $-4 \cdot 4$ to $2 \cdot 9$ & 0.68 \\
\hline Social activities & $43 \cdot 8(31 \cdot 6)$ & $47 \cdot 9(32 \cdot 2)$ & $41 \cdot 5(30 \cdot 2)$ & $45 \cdot 0(28 \cdot 5)$ & $3 \cdot 1$ & $-4 \cdot 0$ to $10 \cdot 3$ & $0 \cdot 38$ \\
\hline Outside activities & $22 \cdot 3(22 \cdot 0)$ & $28 \cdot 3(28 \cdot 2)$ & $20 \cdot 6(23 \cdot 5)$ & $29 \cdot 2(29 \cdot 6)$ & 4.9 & $-2 \cdot 2$ to $12 \cdot 0$ & $0 \cdot 18$ \\
\hline Self initiation & $53.9(15.9)$ & $58 \cdot 0(18 \cdot 4)$ & $53 \cdot 0(18 \cdot 7)$ & $56 \cdot 1(19 \cdot 2)$ & $0 \cdot 2$ & $-3 \cdot 8$ to $4 \cdot 1$ & 0.94 \\
\hline Frequency & $42.9(19 \cdot 0)$ & $45 \cdot 6(21 \cdot 1)$ & $41 \cdot 0(19 \cdot 0)$ & $45.6(21.9)$ & 3.9 & -0.7 to 8.5 & $0 \cdot 10$ \\
\hline Speed & $57 \cdot 3(14 \cdot 6)$ & $63 \cdot 4(16 \cdot 3)$ & $54 \cdot 7(15 \cdot 0)$ & $61 \cdot 3(18 \cdot 7)$ & $2 \cdot 4$ & $-2 \cdot 3$ to $7 \cdot 0$ & $0 \cdot 31$ \\
\hline Efficiency & $60 \cdot 3(12 \cdot 3)$ & $65 \cdot 1(15 \cdot 0)$ & $58.6(16 \cdot 0)$ & $63.5(17.5)$ & $1 \cdot 8$ & -1.5 to $5 \cdot 1$ & 0.29 \\
\hline Overall score & $52 \cdot 6(14 \cdot 1)$ & $57 \cdot 4(17 \cdot 7)$ & $51 \cdot 2(16 \cdot 3)$ & $55.5(18.5)$ & $1 \cdot 1$ & $-2 \cdot 4$ to 4.6 & 0.53 \\
\hline
\end{tabular}

^Difference between two groups adjusted for whether hip or knee was replaced.

TABLE VI-Patients' opinions of their health after operation analysed according to type of anaesthetic they received. Values are numbers (percentages)

\begin{tabular}{|c|c|c|c|c|c|}
\hline & $\begin{array}{c}\text { General } \\
\text { anaesthesia }\end{array}$ & $\begin{array}{c}\text { Regional } \\
\text { anaesthesia }\end{array}$ & $\begin{array}{c}\text { Estimated difference } \\
\text { between } \\
\text { group means } \\
(\%)\end{array}$ & $\begin{array}{l}95 \% \text { Confidence } \\
\text { interval } \\
(\%)\end{array}$ & p Value \\
\hline \multicolumn{6}{|l|}{ Overall mobility: } \\
\hline Improved & $56(88)$ & $60(92)$ & 5 & -6 to 15 & 0.36 \\
\hline No change & $5(8)$ & $4(6)$ & & & \\
\hline Worse & $3(5)$ & $1(2)$ & & & \\
\hline \multicolumn{6}{|l|}{ Overall pain: } \\
\hline Improved & $61(95)$ & $63(97)$ & 2 & -5 to 8 & 0.99 \\
\hline No change & $1(2)$ & $2(3)$ & & & \\
\hline Worse & $2(3)$ & & & & \\
\hline \multicolumn{6}{|c|}{ Memory and concentration: } \\
\hline Improved & $1(2)$ & $3(5)$ & & & \\
\hline No change & $52(81)$ & $52(80)$ & & & \\
\hline Worse & $11(17)$ & $10(15)$ & -2 & -15 to 11 & 0.78 \\
\hline \multicolumn{6}{|l|}{ Opinion of anaesthetic: } \\
\hline Very satisfied & $59(92)$ & $54(83)$ & -10 & -22 to 1 & $0 \cdot 08$ \\
\hline Quite satisfied & $3(5)$ & $9(14)$ & & & \\
\hline Not very satisfied & $2(3)$ & $3(5)$ & & & \\
\hline \multicolumn{6}{|c|}{ Opinion of early progress: } \\
\hline Very satisfied & $52(81)$ & $49(75)$ & -6 & -20 to 8 & 0.42 \\
\hline Quite satisfied & $9(14)$ & $6(9)$ & & & \\
\hline Not very satisfied & $3(5)$ & $10(15)$ & & & \\
\hline \multicolumn{6}{|c|}{ Opinion of progress at 3 months: } \\
\hline Very satisfied & $44(69)$ & $50(77)$ & 8 & -7 to 24 & $0 \cdot 30$ \\
\hline Quite satisfied & $14(22)$ & $9(14)$ & & & \\
\hline Not very satisfied & $6(9)$ & $6(9)$ & & & \\
\hline
\end{tabular}

\section{Discussion}

Surgery is being offered to an increasing proportion of the over $60 \mathrm{~s}$. Indeed, half of all people reaching the age of 65 subsequently have one or more operations. ${ }^{26}$ Impairment of mental function occurs in all patients to a greater or lesser degree after an operation and is usually of short duration. This may be directly due to the lingering effects of anaesthetic drugs, postoperative analgesics, or other factors that contribute to the postoperative fatigue state. ${ }^{27}$ Concern that the central effect of general anaesthetic agents may precipitate organic mental symptoms or cause a deterioration in function in those who are vulnerable has caused anaesthetists to turn to regional anaesthesia especially in older patients.

Similarly, the use of intramuscular and intravenous narcotics is associated with detectable intellectual impairment in elderly patients in the first few postoperative days, and this may lead to increasing use of epidural infusions for postoperative analgesia. Bed rest, inactivity, and the supine position all exert a deleterious effect on psychomotor function. ${ }^{28}$ Starvation and deprivation of sleep are other factors that must be taken into account during the days immediately after an operation. Yet there remains the possibility that these factors, which cause problems in the early postoperative period, also cause problems after the patient has been discharged. Indeed, confusion has been shown to be a contributory factor in $10 \%$ of early unplanned readmissions of elderly patients to hospital. ${ }^{29}$

Our data on inpatients failed to confirm a shorter time to mobilisation ${ }^{30}$ and a reduced length of stay in hospital $^{13}$ with regional anaesthesia but supported those studies that have shown no overall difference in postoperative course between patients given either general or regional anaesthesia provided that the patients are managed scrupulously to avoid known potentially damaging events. ${ }^{141}$ Similarly, we cannot conclude that one anaesthetic technique is better than the other on grounds of mortality and morbidity as the numbers of deaths and complications were small and not obviously different in the two groups. General anaesthesia for total hip replacement would seem to entail a greater demand for blood transfusion, as has been shown previously, ${ }^{32}$ yet patients receiving regional anaesthesia for either hip or knee replacement required significantly greater amounts of colloid to maintain their intravascular volume, presumably to compensate for the sympathetic vasodilatation, despite the use of ephedrine to maintain blood pressure.

The significant improvement in choice reaction time at the three month follow up in patients who had received a general anaesthetic compared with no change in the scores achieved by those who had received a regional anaesthetic was the only measure of cognitive function that changed. At least one scale would be expected to show a difference between the groups simply because of the number of comparisons performed. No good reason exists why this particular function should be altered by general anaesthesia but remain unchanged after regional anaesthesia.

The overall results of the tests of cognitive function suggest that neither anaesthetic technique had any noticeable long term effect on mental function. Furthermore, the inclusion of a control group that did not receive an anaesthetic or have an operation suggested that there was no change over time with the tests used: the tests did not show any effects of practice or any evidence of a decrease in score at three months.

Interestingly, 11 patients in the group receiving general anaesthesia and 10 in the group receiving regional anaesthesia thought that their memory and concentration had deteriorated over the three months. This perceived deficit was not detected by our tests. These patients tended to have an above average IQ score as measured by the national adult reading test but achieved lower than expected scores on other tests of cognitive function. They may represent a subgroup of 
the population who have a more acute perception of any deterioration in memory than the general population or they may have had a subclinical depressive illness. Our tests may not be sensitive enough to detect a small change in function that can be noticed by patients with a high degree of self awareness and insight. This subjective feeling of "things not being quite right" has been reported previously and may last for up to 30 days after general anaesthesia in young volunteers. ${ }^{334}$ Conversely, there is evidence that patients may report themselves as fully recovered and back to normal and still have a measurable decrease in function. ${ }^{3536}$

In conclusion, using objective and subjective measures of both cognitive and functional competence, we found that modern anaesthesia, either general or regional, seemed to have no significant long term effects on mental function in elderly patients.

We thank Astra Pharmaceuticals for financial support, $\mathrm{Ms}$ $H$ Altman for conducting the interviews with patients and the psychometric assessments, and Mrs R Douglas and Mrs H P Hughes for administrative help.

1 Bulstrode C. Keeping up with orthopaedic epidemics. Br Med f 1987;295:514. 2 Bedford PD. Adverse cerebral effects of anaesthesia on people. Lance 1955;ii:259-63.

1955;ii:259-63.
Simpson BR, Williams M, Scott JF, Crampton-Smith A. The effects of Simpson BR, Williams M, Scott JF, Crampton-Smith A. The effects
anaesthesia and elective surgery on old people. Lancet 1961;ii:887-93.

Wollman SB, Orkin LR. Postoperative human reaction time and hypocarbia during anaesthesia. Br f Anaesth 1968;40:920-6.

5 Murrin KR, Nagarajan TM. Hyper-ventilation and psychometric testing. Anaesthesia 1974;29:50-8.

6 Prior FN, Chander P. Air as a vapourizing gas. Cognitive functions in elderly patients undergoing anaesthesia. Br $\mathcal{F}$ Anuesth 1982;54:1207-11.

7 Rollason WN, Robertson GS, Cordiner CM, Hall DJ. A comparison of mental function in relation to hypotensive and normotensive anaesthesia in the elderly. Br f Anaesth 1971;43:561-5.

8 Thompson GE, Miller RD, Stevens WC, Murray WR. Hypotensive anesthesia for total hip arthroplasty. Anesthesiology 1978;48:91-6.

9 Hodkinson HM. Mental impairment in the elderly. $f R$ Coll Physicians Lond 1973;7:305-17.

10 Blundell E. A psychological study of the effects of surgery on eighty-six elderly patients. British fournal of Social and Clinical Psychology 1967;6:297-303.

1 Millar HR. Psvchiatric morbidity in elderly surgical patients. Br f Psychiatry $1981 ; 138: 17-20$

12 Berggren D, Gustafson Y, Eriksson B, et al. Postoperative confusion after anesthesia in elderly patients with femoral neck fractures. Anesth Analg 1987;66:497-504
3 Hole A, Teriesen T, Breivik $\mathrm{H}$. Epidural versus general anaesthesia for total hip arthroplasty in elderly patients. Acta Anaesthiol Scand 1980;24:279-87. 4 Riis J, Lomholt B, Haxholdt $\mathrm{O}$, et al. Immediate and long-term mental recovery from general versus epidural anaesthesia in elderly patients. Acta Anaesthiol Scand 1983;27:44-9.

15 Chung F, Meier R, Lautenschlager E, et al. General or spinal anesthesia; which is better in the elderly? Anesthesiology 1987;67:422-7.

16 Ghoneim MM, Hinrichs JV, O'Hara MW, et al. Comparison of psychologic and cognitive function after general or regional anesthesia. Anesthesiology 1988;69:507-15.

17 Zelen $M$. A new design for randomised clinical trials. $N$ Engl f Med 1979;300:1242-5.

18 Zelen M. Alternatives to classic randomised trials. Surg Clin North Am 1981;61:1425-32

19 Nelson HE. National adult reading test (NART) test manual. Windsor: National Foundation for Educational Research-Nelson, 1982.

20 Hindmarch I, Parrott AC. Repeated dose comparison of nomifensine, unipranine and placebo on subjective assessments of sleep and objective measures of psychomotor performance. Br f Clin Pharmacol 1976;4: 1675-735.

21 Hindmarch I. 1-4 Benzodiazepine, temazepam (K3917). Its effect on some psychological parameters of sleep amd behaviour. Arzneimittelforschung 1975;25:1836-9.

22 Kendrick DC. The Kendrick cognitive tests for the elderly. Windsor: National Foundation for Educational Research-Nelson, 1986.

23 Sarno JE, Sarno MT, Levita E. Functional life scale. Arch Phys Med Rehabil $1973 ; 54: 214-20$

24 McNair DM, Kahn RJ. Self-assessment of cognitive deficits. In: Crook T, Ferris S, Bartus R, eds. Assessment in geriatric psychopharmacolgy. Connecticut: Mark Powly, 1983:137-44.

25 Newcombe RG. Explanatory and pragmatic estimates of the treatment effect when deviations from allocated treatment occur. Stat Med 1988;7:1179-86.

26 Davenport HT. Anaesthesia in the elderlv. London: Heinemann Medical, 1986:ix.

27 Anonymous. Postoperative fatigue [Editorial]. Lancet 1979;i:84-5.

28 Edwards H, Rose EA, Schorow M, King TC. Postoperative deterioration in psards H, Rose EA, Schorow M, King TC. Pos
psychomotor function. FAMA 1981;245:1342-3.

29 Williams EI, Fitton F. Factors affecting early unplanned readmission of elderly patients to hospital. Br Med $\mathcal{F} 1988 ; 297: 784-7$.

30 Bigler D, Adelhoj B, Petring OU, Busch P, Kalhke P. Mental function and morbidity after acute hip surgery during spinal and general anaesthesia. Anaesthesia 1985;40:672-6.

31 Karhunen U, Jonn $\mathrm{G}$. A comparison of memory function following local and general anaesthesia for extraction of senile cataract. Acta Anaesthiol Scand 1982;26:291-6.

32 Thorburn J, Louden JR, Vallance R. Spinal and general anaesthesia in total hip replacement: frequency of deep vein thrombosis. Br $\mathcal{F}$ Anaesth 1980;52: $1117-20$.

33 James FM. The effects of cyclopropane anesthesia without surgical operation in mental functions of normal man. Anesthesiology 1969;30:264-72.

34 Davison LA, Steinhelber JC, Eger EI, Stevens WC. Psychological effects of halothane and isoflurane anesthesia. Anesthesiology 1975;43:313-24.

35 Egbert LD, Oech SR, Eckenhoff JE. Comparison of the recovery from methohexital and thiopental anesthesia in man. Surg Gynecol Obstet 1959;109:427-30.

36 Herbert $M$, Healy TEJ, Bourke JB, Fletcher IR, Rose JM. Profile of recovery after general anaesthesia. Br Med f 1983;286:1539-42.

(Accepted 3 April 1990)
Departments of Clinical Pharmacology and Medical Statistics, North

Staffordshire Health

Authority, Stoke on

Trent ST 4 6QG

Sandra Kuhn, SRN, research sister

Karen Cooke, SEN, research nurse

Michael Collins, PHD, district medical statistician

J Mary Jones, PHD, district medical statistician

John C Mucklow, FRCP, consultant clinical

pharmacologist

Correspondence to:

Mrs Kuhn.

\title{
Perceptions of pain relief after surgery
}

\author{
Sandra Kuhn, Karen Cooke, Michael Collins, J Mary Jones, John C Mucklow
}

\section{Abstract}

Objective-To assess patients' satisfaction with postoperative pain relief.

Design-A descriptive and questionnaire study of patients' experience.

Setting-Two surgical and two gynaecological wards.

Patients -50 Patients admitted to hospital for cholecystectomy and 51 admitted for hysterectomy.

Main outcome measures-Visual analogue scales with no divisions were completed by the patients immediately after each dose of postoperative analgesia was administered throughout their stay in hospital. A questionnaire completed on the fifth postoperative day recorded patients' recollections of their experience. Opinions were also sought from medical and nursing staff.

Results-During the first $\mathbf{2 4}$ hours after surgery recorded pain levels were $60 \%$ of the maximum and were not influenced by age, sex, or the type of operation performed. The median interval between the return of pain and a further injection of analgesic was 2 hours (interquartile range 1 to 3.5 hours). Expectations of pain relief were low, and for $70 \%$ of the patients the pain was at least as bad as they had expected. Only half of the medical and nursing staff questioned thought that postoperative analgesia should relieve pain completely; drugs were prescribed and administered with too little attention to the patient's response and too much concern about adverse effects and opioid dependence.

Conclusions - The results suggest that the standard of postoperative pain relief is poor because of inadequate education of patients in what to expect (and demand), and of medical and nursing staff in how to prescribe and administer analgesia with reference to individual drug response.

\section{Introduction}

Ineffective relief of postoperative pain is an unacceptable but common sequel to surgery. Cohen found that $37 \%$ of patients who had elective abdominal operations were in severe pain afterwards, ${ }^{\prime}$ and $42 \%$ of patients questioned by Cronin et al after similar procedures described the pain they experienced as "very unpleasant indeed.".

The reasons for inadequate pain relief include 